\title{
Effect of different forms of information produced for cancer patients on their use of the information, social support, and anxiety: randomised trial
}

\author{
R B Jones, J Pearson, A J Cawsey, D Bental, A Barrett, J White, C A White, W H Gilmour
}

\begin{abstract}
Objective To explore the hypothesis that different methods of selecting and printing information for cancer patients could improve emotional support by affecting interaction with others, and so lead to improved psychological wellbeing.

Design Randomised trial with eight groups (three factors, $2 \times 2 \times 2$ ). Data collected at recruitment and three month follow-up.

Participants 400 patients starting radiotherapy, of whom 325 with breast or prostate cancer and complete anxiety and depression data were included in the analysis.

Interventions Printed booklets: half had only general information from CancerBACUP about each patient's cancer and half had personalised information from the patient's medical record plus selected general information; half were composed of information chosen interactively by the patient and half were produced automatically with a larger volume of material; and half had additional advice on anxiety management and half did not.
\end{abstract}

Main outcome measures Patients' views of the information, use of their booklets with others; change in reported social support; change in anxiety and depression.

Results The larger booklets produced automatically were more likely to be found useful and to tell patients something new and less likely to be seen as too limited than the booklets produced interactively, but they were also more likely to overwhelm some patients. Personalised booklets were more likely than general booklets to tell patients something new. There was no difference in patients' perceived understanding of their cancer by any of the intervention factors. Patients with personalised information were more likely to show their booklets to others and to think it helped in discussing their cancer or its treatment. There were no major differences in social support, anxiety, or depression by any intervention factors.

Conclusions Patients were more likely to show personalised information to their confidants than general information. Further research is needed into the effects of sharing information on patients' social support and anxiety.

Trial registration US Government Clinical Trials Database NCT00127465

\section{Introduction}

Anxiety and depression are important and common comorbidities in cancer and may affect survival. ${ }^{12}$ Providing information and social support may improve patients' psychological wellbeing, ${ }^{3}{ }^{4}$ but different patients may have different information preferences ${ }^{56}$ and coping styles. ${ }^{7}$ Most cancer patients want as much information as possible, ${ }^{5}$ and information-seeking behaviours must be taken into account in the way information is presented. ${ }^{8}$ The two main coping strategies for dealing with cancer are "monitoring" and "blunting"; patients fare better when the information they receive is tailored to their own coping style. ${ }^{7}$ Coping style also affects patients' desire for social support. Some argue that most women with breast cancer want to talk about and share their feelings with others, whereas most men with prostate cancer would rather not. ${ }^{9}$ Availability of a confidant and a means by which a patient can engage support is important but also depends on coping style. Direct communication of cancer information within a family unit has also been shown to be associated with lower levels of anxiety. ${ }^{10}$

In a previous study we found that patients preferred personalised information (based on their own medical records) to general information and that they were more likely to show it to family members. ${ }^{11}$ Unexpectedly, we found that patients with personalised information showed better improvement in anxiety over three months than those with more general information. We knew that patients with personalised information were more likely to show it to someone at home and hypothesised that this might be partly responsible. We have now carried out a randomised trial, with similar patients and setting, to explore the hypothesis that different methods of selecting and printing information for cancer patients could improve emotional support by affecting interaction with others, and so lead to improved psychological wellbeing.

\section{Participants and methods}

\section{Participants}

Location and timing of the study-Patients were recruited at the Beatson Oncology Centre between November 2001 and March 2002. The centre provides specialised non-surgical cancer treatment for patients throughout western Scotland. Recruitment started at the main site, but logistical problems resulted in the study moving to the newly opened Tom Wheldon Centre (a "satellite" centre of the Beatson Oncology Centre at Gartnavel Hospital) recruiting patients there between February 2002 and March 2003.

Sample size-The target sample was 400 patients, giving $80 \%$ power to find a difference of $40-27 \%$ in improved anxiety

Appendices 1-10, providing further information about the study, are on bmj.com 
between (for example) 200 given personalised information and 200 given general information only. (This was based on conservative estimates of changes in anxiety from our previous work but not taking into account possible interactions between factors).

Patient selection-A total of 874 patients identified from outpatient appointment diaries as starting radiotherapy treatment for breast, prostate, cervical, or laryngeal cancer were registered with the study, and their medical records were reviewed (figure). Of these, 604 patients were sent a letter explaining the study, and 270 were excluded. Reasons for exclusion included receiving palliative care, severe pain or symptoms causing distress, having cancer at other sites, having no spoken English, receiving treatment for psychological or psychiatric problems, visual or mental handicap, and case notes being unavailable, ambiguous, or illegible.

\section{Recruitment}

On each patient's attendance at the hospital a researcher (JP) further explained the study and sought written consent. She excluded $41(6.8 \%)$ patients at recruitment-20 who did not give informed consent, 14 who were "missed" (that is, not contacted when they attended) for logistical reasons, and seven who were excluded at the end of the study when the target sample size was reached.

Patients refusing-Of the 563 patients invited to take part, 400 $(71 \%)$ consented. Of the 163 who refused, 44 gave no reason, 25 said they were not interested or could not be bothered, 21 said they did not want any information, 16 said they had enough information, 18 were in a hurry or had someone waiting, 13 were feeling ill or could not hear well, 12 did not like filling forms, nine were already in a trial and did not want to take part in another, and five gave other reasons. The $29 \%$ of patients who refused to take part were more likely to live in deprived areas (36\% of patients in deprivation categories 5-7 refused compared with $25 \%$ of those in categories $1-4 ; \chi^{2}=8.5 ; 1 \mathrm{df} ; \mathrm{P}=0.003$ ).

Patients recruited-The 400 patients recruited comprised 275 $(69 \%)$ women and 125 men with ages ranging from 28 to 82 years with mean age 59 (median 61). Of these, 348 completed follow-up. Patients had had their cancer diagnosed between five and 312 weeks before recruitment. Two thirds $(262,68 \%)$ of the patients had breast cancer, and just under a third $(118,31 \%)$ had prostate cancer. One woman had cervical cancer, and two men and one woman had laryngeal cancer. The breast cancer patients had been diagnosed for a shorter time on average than had the prostate cancer patients (19 weeks $v 43$ weeks, $\mathrm{P}<0.001$ ).

Recruitment data-At recruitment, patients were asked to complete a questionnaire at home (see appendix 5 on bmj.com for details) and to bring it to their next appointment. This included questions on their previous computer use, information preferences ${ }^{56}$ and coping style, ${ }^{7}$ household, and confidant (the person they were most likely to discuss their cancer with); Helgeson's social support questionnaire (HSSQ), ${ }^{12}$ and the hospital anxiety and depression scale (HADS). ${ }^{13}$

\section{Randomisation}

All patients were offered booklets based on information from the website of CancerBACUP, a cancer information and support service for patients (www.cancerBACUP.org.uk). Before recruitment, we prepared 400 randomisation sealed envelopes in 10 blocks of 40 using random number tables. We randomised patients to eight groups defined by the three binary factors under study: (a) half received personalised information that included data from their medical records, whereas half had only

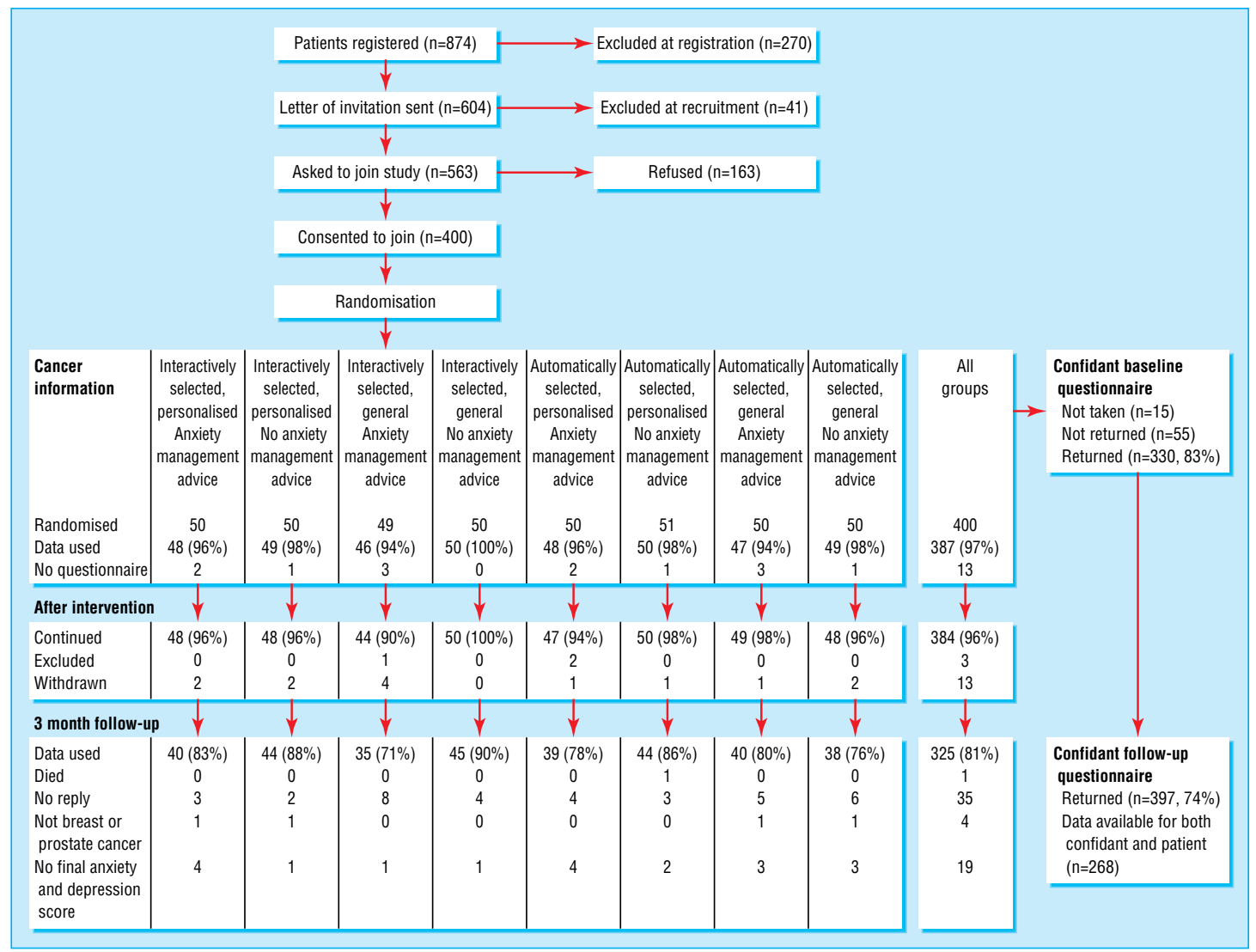

Patient flow through study 
general information from CancerBACUP for their cancer; $(b)$ half chose information interactively by selecting it with a computer at the oncology centre, and half had a larger volume of material in booklets that were produced automatically; and $(c)$ half had additional anxiety management advice, and half did not. An error in the randomisation envelopes resulted in the misallocation of one patient, with one of the eight groups having 51 patients and another only 49 (see figure).

\section{Interventions}

Choices made by patients in our previous study ${ }^{11}$ guided the information we offered. The patients given booklets that were produced automatically (containing 40-47 sections) did not use the oncology centre computer. Patients provided with general information only received the booklets Understanding Radiotherapy, Diet and the Cancer Patient, and the appropriate cancer-specific booklet (such as Understanding Breast Cancer). Patients provided with general information and who selected information interactively could choose sections from the above three booklets and from three further CancerBACUP booklets (Cancer and Complementary Therapies, Feeling Better Controlling Pain, and Sexuality and Cancer). These six booklets had a total of 78 sections, and the patients were allowed to choose up to 10 sections from a menu. This relatively limited choice was decided partly for pragmatic reasons (such as time available for users to select topics) but mainly in order to test the difference between a small but carefully selected subset of information and a larger more general document. Patients given anxiety management advice had an extra few pages with self help advice based on work in cognitive behaviour therapy for anxiety.

The patients allocated personalised information that was produced automatically received selected information from the three general booklets plus information from their medical records. The less relevant sections in the three booklets (determined by patient's cancer type, treatment, age, and sex) were omitted, so that patients received slightly shorter booklets than did the patients given general information. Patients allocated personalised information that they chose interactively could select topics from their medical record such as "problem list," "treatment list," or "your cancer." For the patients who chose information interactively, we recorded the sections chosen, whether they required help with the computer, whether they used the computer mouse or the touch screen. We also noted those patients who did not wish to take a booklet. (See appendix 6 on bmj.com for details of the intervention.)

\section{Follow-up data}

Patients were sent follow-up questionnaires three months later. The questionnaires included Helgeson's social support questionnaire, the hospital anxiety and depression scale, and questions about the patients' use and opinions of the booklets and their reported understanding of cancer. We sent reminders at three and six weeks later to non-responders.

\section{Statistical analysis}

Of the 400 patients we recruited (figure), 384 (96\%) completed the intervention and $348(87 \%)$ returned the follow-up questionnaire. Completed data for the hospital anxiety and depression scale were available for $329(82 \%)$ patients. Here we present the results, based on an intention to treat analysis, for the 325 patients with cancer of the breast or prostate, excluding the four patients with cervical and laryngeal cancer for clarity. (Appendix 2 on bmj.com compares the 325 patients included with the 75 excluded from analysis, and appendix 4 presents analysis for all
400 patients, with estimated values for those not completing follow-up.)

We compared both the differences in the anxiety and depression scores at recruitment and at follow-up and in the proportions of patients with scores $\geq 8$ (cases or probable cases of anxiety or depression). Patients answered questions about the booklets on Likert scales, and we grouped these according to the modal answer into binary scores. Helgeson's social support questionnaire produces four scores-instrumental, informational, and emotional support (20="best") and "negative interactions" ( $50=$ "worst").

Analyses to ensure robustness of results included using difference in scores and in scores grouped by tertiles and quartiles. We examined patients' views and use of the booklets and differences in the social support and the anxiety and depression scores between recruitment and three months by means of general linear models and multiple logistic regression as appropriate. To compensate for the problem of finding statistically significant results by chance because of multiple testing, we considered significant results to be important only if they formed a consistent pattern from various analyses.

\section{Results}

\section{Baseline characteristics}

At recruitment, there was no difference between the intervention groups in terms of anxiety, depression, social support, age, sex, or length of diagnosis (table 1). Of the patients who answered the questions, 326/375 (87\%) were satisfied or very satisfied with the cancer information they had already received, 231/373 (62\%) had read at least one CancerBACUP booklet. Only 52/382 (14\%) had obtained health information themselves from the internet, but $67(18 \%)$ had been given information from the internet by someone else, and $164(43 \%)$ had never used a computer before.

Among the 325 patients with breast or prostate cancer who completed the study, all four of the social support scales were skewed towards having lots of support-median scores were 17 for informational, 20 for emotional, and 20 for instrumental support, and 13 for "negative interactions" (appendix 8 on bmj.com). A third $(99,30 \%)$ had anxiety and 43 (13\%) had depression (scores of $\geq 8$ ). General linear models used to predict anxiety and depression scores and multiple logistic regression to predict cases or borderline cases of anxiety or depression produced similar results. The negative interactions measure of social support predicted both anxiety and depression at baseline (appendix 7 on bmj.com).

\section{Interactive selection of information}

For the 190 patients who selected their cancer information, the average time spent using the computer (including explanation given by the researcher) was 9 minutes (range 2-30). A third required help in using the computer; two thirds chose to use the touch screen, and a third used the mouse. Of the $82(43 \%)$ patients who had not used a computer before, only two chose to use the mouse. The researcher operated the computer for four people.

On average, patients chose eight sections (range 0-10); there was no difference by intervention or other factors. Patients with breast or prostate cancer were similar in the sections they chose (see box). Sections chosen by both men and women and that were available to those given information produced automatically were "healthy eating," "side effects," "causes," "general tips," and "why prescribed." Other popular choices for men were "radiotherapy" and "prostate cancer" and for women were "living 
Table 1 Baseline characteristics of 400 cancer patients by type of cancer information provided. Values are numbers (percentages) of patients unless stated otherwise

\begin{tabular}{|c|c|c|c|c|c|c|}
\hline & \multicolumn{2}{|c|}{ Selection of information } & \multicolumn{2}{|c|}{ Personalisation of information } & \multicolumn{2}{|c|}{ Anxiety management advice } \\
\hline & Interactive & Automatic & General & Personalised & None & Present \\
\hline \multicolumn{7}{|l|}{ With anxiety or depression $(n=384)^{*}$ : } \\
\hline Anxiety & $64(34)$ & $59(31)$ & $67(35)$ & $56(29)$ & $57(29)$ & $66(35)$ \\
\hline Depression & $32(17)$ & $24(12)$ & $31(16)$ & $25(13)$ & $31(16)$ & $25(13)$ \\
\hline \multicolumn{7}{|l|}{ In worst quarter for social support†: } \\
\hline Informational support $(\mathrm{n}=377)$ & $56(30)$ & $55(29)$ & $55(29)$ & $56(30)$ & $56(29)$ & $55(30)$ \\
\hline Emotional support $(\mathrm{n}=381)$ & $56(30)$ & $55(29)$ & $52(28)$ & $59(31)$ & $58(30)$ & $53(28)$ \\
\hline Instrumental support $(\mathrm{n}=381)$ & $61(32)$ & $57(30)$ & $59(31)$ & $59(31)$ & $61(31)$ & $57(31)$ \\
\hline Negative interactions $(\mathrm{n}=360)$ & $42(23)$ & $38(21)$ & $34(19)$ & $46(25)$ & $37(20)$ & $43(25)$ \\
\hline Mean (SD) age (years) $(n=400)$ & $59(10.3)$ & $59(10.9)$ & $60(10.3)$ & $59(10.9)$ & $59(10.4)$ & $59(10.8)$ \\
\hline Women $(n=400)$ & $72(143)$ & $66(132)$ & $65(130)$ & $72(145)$ & $69(139)$ & $68(136)$ \\
\hline $\begin{array}{l}\text { Mean (interquartile range) length of diagnosis } \\
\text { (weeks) ( } n=388 \text { ) }\end{array}$ & $27(10-32)$ & $26(12-32)$ & $27(12-33)$ & $26(10-32)$ & $27(11-33)$ & $26(11-32)$ \\
\hline
\end{tabular}

${ }^{*}$ Scores $\geq 8$ on the hospital anxiety and depression scale.

†Measured with Helgeson's social support questionnaire. Distributions of informational, emotional, and instrumental social support were all markedly skewed, with the median=maximum score of 20 .

with surgery" and "feelings." The last section, from the booklet Cancer and Complementary Therapies, was not issued to those given information produced automatically. The other two booklets available exclusively to those who selected their information (Feeling Better Controlling Pain and Sexuality and Cancer) were not frequently chosen.

\section{Three month follow-up}

Patients' opinions of the booklets and perceived understanding-The booklets produced automatically, which were larger than those produced interactively by patients, were more likely to be found useful and to tell the patient something new and less likely to be seen as too limited, but they were also more likely to overwhelm some patients than the booklets produced interactively (table 2). The booklets with personalised information were more likely than those with only general information to tell the patient something new. The patients given automatically produced booklets had higher overall satisfaction scores than those who produced their booklets interactively $(54 \% v 47 \%$ with score $>2$; $\mathrm{P}=0.02$ from general linear models). When asked to rate their current understanding of their cancer, $26(8 \%)$ rated it less than

Most popular sections of cancer information booklets chosen by the 94 patients who selected general cancer information

Breast cancer patients $(n=65)$

- Healthy eating (Diet and the Cancer Patient) $(\mathrm{n}=23)$

- Possible causes (Understanding Breast Cancer) $(\mathrm{n}=21)$

- Side effects (Understanding Radiotherapy) $(\mathrm{n}=19)$

- General tips (Understanding Radiotherapy) $(\mathrm{n}=19)$

- Why prescribed (Understanding Radiotherapy) $(\mathrm{n}=18)$

- Living with surgery (Understanding Breast Cancer) $(\mathrm{n}=17)$

- Feelings (Cancer and Complementary Therapies) $(\mathrm{n}=17)$

Prostate cancer patients $(\mathbf{n}=29)$

- Side effects (Understanding Radiotherapy) $(\mathrm{n}=13)$

- Radiotherapy (Understanding Prostate Cancer) $(\mathrm{n}=10)$

- Why prescribed (Understanding Radiotherapy) $(\mathrm{n}=10)$

- Healthy eating (Diet and the Cancer Patient) $(\mathrm{n}=9)$

- Prostate cancer (Understanding Prostate Cancer) $(\mathrm{n}=8)$

- Possible causes (Understanding Prostate Cancer) $(\mathrm{n}=8)$

- General tips (Understanding Radiotherapy) $(\mathrm{n}=7)$ they had done at recruitment, $188(58 \%)$ rated it the same, and $110(34 \%)$ rated it better, but there was no difference by any of the intervention factors. One hundred and thirteen patients $(35 \%)$ made positive comments about the booklets and 38 (12\%) made negative comments, and patients with personalised booklets were more likely to mention the relevance of the information than those given only general information $\left(41 \% v 15 \% ; \chi^{2}=9.3\right.$, 1df; $\mathrm{P}=0.002$ ).

Use of the booklets with others-Compared with patients with general information only, patients with personalised information were more likely to show their booklets to their "confidant" $(85 \%$ v $\left.70 \% ; \chi^{2}=10.1,1 \mathrm{df} ; \mathrm{P}=0.001\right)$, to someone else in the household ( $\left.32 \% v 19 \% ; \chi^{2}=6.8,1 \mathrm{df} ; \mathrm{P}=0.009\right)$, and to someone outside the household $\left(33 \% v 22 \% ; \chi^{2}=4.3,1 \mathrm{df} ; \mathrm{P}=0.04\right)$. There was no difference for the other two intervention factors. Those with personalised information were more likely than those with general information only to think that it helped in discussing their cancer or its treatment $\left(80 \% v 65 \% ; \chi^{2}=4.2,1 \mathrm{df} ; \mathrm{P}=0.04\right)$.

Changes in social support-Patients' social support scores showed a considerable range of changes from baseline to followup. Changes in informational support ranged from - 12 to 12 , in emotional support from -10 to 7 , in instrumental support from -8 to 7 , and in "negative interactions" from -11 to 22 . There were some unexpected differences by the intervention factors among patients who had shown their booklets to their confidant (table 3). On the "negative interactions" scale, $42 \%$ of patients with personalised information deteriorated, compared with only $24 \%$ of those with general information only. Patients who were given anxiety management advice were more likely to have deteriorated on the instrumental support scale than those not given the advice $(27 \% v 13 \%)$.

Changes in anxiety and depression-At follow-up, 145 patients (45\%) had improved anxiety scores. The percentage improvement ranged from 33\% (13/39) in those given automatically produced, personalised information with anxiety management advice to $55 \%(21 / 38)$ in those given automatically produced, general information with no anxiety management advice, but there were no significant differences between the three intervention factors (allowing for interactions between these). There was no difference between mean anxiety scores at baseline (5.9) and follow-up (6.0), nor in the percentage of patients with scores $\geq 8$ at baseline (31\%) and follow-up (33\%). None of the three intervention factors was a significant predictor of change in anxiety in a general linear model (table 4). Patients who had 
Table 2 Views of 325 cancer patients* at follow-up on booklets of cancer information provided. Results of multiple logistic regression analysis of views by type of information provided $\dagger$

\begin{tabular}{|c|c|c|}
\hline \multirow[b]{2}{*}{ Views expressed } & \multicolumn{2}{|c|}{ Type of information and other significant factors in analysis } \\
\hline & Factor ( $\mathrm{P}$ value) & Percentage $\begin{array}{c}\text { (No) of patients in cross } \\
\text { tabulation }\end{array}$ \\
\hline \multirow{3}{*}{$\begin{array}{l}\text { Booklet very } \\
\text { useful }\end{array}$} & Selection of information (0.011) & $\begin{array}{l}67 \text { (102) automatic v } 54 \text { (77) } \\
\text { interactive }\end{array}$ \\
\hline & $\begin{array}{l}\text { Personalisation of information } \\
(0.243)\end{array}$ & $\begin{array}{c}62 \text { (96) personalised } v 59(83) \\
\text { general }\end{array}$ \\
\hline & $\begin{array}{l}\text { Anxiety management advice } \\
(0.267)\end{array}$ & 64 (87) advice $v 58$ (92) no advice \\
\hline \multirow{4}{*}{$\begin{array}{l}\text { Booklet definitely } \\
\text { told them } \\
\text { something new }\end{array}$} & Selection of information $(0.040)$ & $\begin{array}{l}55 \text { (84) automatic v } 38 \text { (55) } \\
\text { interactive }\end{array}$ \\
\hline & $\begin{array}{c}\text { Personalisation of information } \\
(0.017)\end{array}$ & $\begin{array}{c}52 \text { (81) personalised } v 41(58) \\
\text { general }\end{array}$ \\
\hline & $\begin{array}{c}\text { Anxiety management advice } \\
(0.798)\end{array}$ & 45 (63) advice $v 48$ (76) no advice \\
\hline & $\operatorname{Sex}(0.001)$ & 60 (55) men $v 41$ (84) women \\
\hline \multirow{4}{*}{$\begin{array}{l}\text { Information } \\
\text { definitely } \\
\text { relevant }\end{array}$} & Selection of information (0.242) & $\begin{array}{l}78 \text { (120) automatic v } 72 \text { (103) } \\
\text { interactive }\end{array}$ \\
\hline & $\begin{array}{l}\text { Personalisation of information } \\
(0.911)\end{array}$ & $\begin{array}{c}75 \text { (115) personalised } v 76(108) \\
\text { general }\end{array}$ \\
\hline & $\begin{array}{l}\text { Anxiety management advice } \\
(0.537)\end{array}$ & 75 (104) advice $v 75$ (119) no advice \\
\hline & $\operatorname{Sex}(0.045)$ & 86 (77) men v 71 (146) women \\
\hline \multirow{4}{*}{$\begin{array}{l}\text { Information } \\
\text { possibly or } \\
\text { definitely easy } \\
\text { to find }\end{array}$} & Selection of information (0.573) & $\begin{array}{l}84 \text { (129) automatic } v 80 \text { (114) } \\
\text { interactive }\end{array}$ \\
\hline & $\begin{array}{c}\text { Personalisation of information } \\
(0.284)\end{array}$ & $83 \quad \begin{array}{c}\text { (127) personalised } v \\
\text { general }\end{array} 81(116)$ \\
\hline & $\begin{array}{l}\text { Anxiety management advice } \\
(0.356)\end{array}$ & 80 (110) advice $v 84$ (113) no advice \\
\hline & Information preference $(0.031)$ & $\begin{array}{l}91 \text { (31) none or only good news } v \\
80 \text { (202) all }\end{array}$ \\
\hline \multirow{4}{*}{$\begin{array}{l}\text { Information } \\
\text { possibly or } \\
\text { definitely } \\
\text { overwhelming }\end{array}$} & Selection of information (0.005) & $\begin{array}{l}27 \text { (41) automatic v } 16(23) \\
\text { interactive }\end{array}$ \\
\hline & $\begin{array}{l}\text { Personalisation of information } \\
(0.465)\end{array}$ & $\begin{array}{c}21 \text { (33) personalised } v 22 \text { (31) } \\
\text { general }\end{array}$ \\
\hline & $\begin{array}{l}\text { Anxiety management advice } \\
(0.493)\end{array}$ & 23 (32) advice $v 20$ (32) no advice \\
\hline & Newspaper read $(0.001)$ & 30 (48) tabloid $v 12$ (16) broadsheet \\
\hline \multirow{4}{*}{$\begin{array}{l}\text { Information } \\
\text { possibly or } \\
\text { definitely too } \\
\text { technical }\end{array}$} & Selection of information (0.382) & 8 (13) automatic $v 7$ (10) interactive \\
\hline & $\begin{array}{c}\text { Personalisation of information } \\
(0.368)\end{array}$ & 7 (11) personalised $v 8$ (12) general \\
\hline & $\begin{array}{l}\text { Anxiety management advice } \\
(0.463)\end{array}$ & 9 (12) advice $v 7$ (11) no advice \\
\hline & Newspaper read $(0.030)$ & 11 (18) tabloid v 4 (5) broadsheet \\
\hline \multirow{3}{*}{$\begin{array}{l}\text { Information too } \\
\text { limited }\end{array}$} & Selection of information (0.029) & $\begin{array}{l}24 \text { (36) automatic } v 36 \text { (51) } \\
\text { interactive }\end{array}$ \\
\hline & $\begin{array}{l}\text { Personalisation of information } \\
(0.795)\end{array}$ & $\begin{array}{l}28 \text { (43) personalised } v 31(44) \\
\text { general }\end{array}$ \\
\hline & $\begin{array}{l}\text { Anxiety management advice } \\
\qquad(0.792)\end{array}$ & 29 (39) advice $v 30$ (48) no advice \\
\hline \multirow{4}{*}{$\begin{array}{l}\text { Information } \\
\text { expected but } \\
\text { not there }\end{array}$} & Selection of information (0.074) & $\begin{array}{l}17 \text { (24) automatic v } 23 \text { (31) } \\
\text { interactive }\end{array}$ \\
\hline & $\begin{array}{l}\text { Personalisation of information } \\
(0.217)\end{array}$ & $\begin{array}{c}17 \text { (24) personalised } v 23 \text { (31) } \\
\text { general }\end{array}$ \\
\hline & $\begin{array}{c}\text { Anxiety management advice } \\
(0.140)\end{array}$ & 17 (22) advice $v 22$ (33) no advice \\
\hline & Used computer before $(0.038)$ & 24 (39) yes v $14(16)$ no \\
\hline \multirow{4}{*}{$\begin{array}{l}\text { Information } \\
\text { possibly or } \\
\text { definitely } \\
\text { changed their } \\
\text { ideas }\end{array}$} & Selection of information (0.283) & $\begin{array}{l}37 \text { (55) automatic } v 31 \text { (44) } \\
\text { interactive }\end{array}$ \\
\hline & $\begin{array}{l}\text { Personalisation of information } \\
(0.915)\end{array}$ & $\begin{array}{c}32 \text { (48) personalised } v 36(51) \\
\text { general }\end{array}$ \\
\hline & $\begin{array}{l}\text { Anxiety management advice } \\
(0.396)\end{array}$ & 35 (47) advice $v 33$ (52) no advice \\
\hline & $\operatorname{Sex}(0.035)$ & 47 (41) men $v 29$ (58) women \\
\hline
\end{tabular}

*Missing data from 27-34 (8\%-11\%) of patients for individual questions.

tPredictor variables included in the analysis were the three information factors (automatic or interactive selection, personalised or general information, anxiety management advice or none); the continuous variables of age and length of diagnosis; and the categorical variables of sex, newspaper read, coping style (monitoring $v$ blunting), ${ }^{7}$ information preference (none or good news only $v$ all information), ${ }^{5}$ and whether used a computer before.
Table 3 Changes in social support scores* of in 224 cancer patients who had shown their cancer information booklets to a confidant. Results of general linear model of change in four social support by type of cancer information provided $†$

\begin{tabular}{|c|c|c|}
\hline \multirow{2}{*}{$\begin{array}{l}\text { Change in } \\
\text { social support } \\
\text { score }^{*}\end{array}$} & \multicolumn{2}{|c|}{ Type of information and other significant factors in analysis } \\
\hline & Factor (P value) & $\begin{array}{c}\text { Percentage }(\mathrm{No}) \text { of patients } \\
\text { deteriorating }\end{array}$ \\
\hline \multirow{4}{*}{$\begin{array}{l}\text { Informational } \\
\text { support }\end{array}$} & Selection of information (0.947) & $\begin{array}{l}30 \text { (34) automatic v } 34 \text { (34) } \\
\text { interactive }\end{array}$ \\
\hline & $\begin{array}{c}\text { Personalisation of information } \\
(0.487)\end{array}$ & 34 (40) personalised $v 0(28)$ general \\
\hline & Anxiety management advice $(0.557)$ & 38 (36) advice $v 28$ (32) no advice \\
\hline & Newspaper read $(0.001)$ & 44 (48) tabloid $v 18$ (18) broadsheet \\
\hline \multirow{3}{*}{$\begin{array}{l}\text { Instrumental } \\
\text { support }\end{array}$} & Selection of information (0.687) & $\begin{array}{l}20 \text { (22) automatic v } 19 \text { (19) } \\
\text { interactive }\end{array}$ \\
\hline & $\begin{array}{l}\text { Personalisation of information } \\
(0.699)\end{array}$ & $\begin{array}{c}18 \text { (21) personalised } v 21(20) \\
\text { general }\end{array}$ \\
\hline & Anxiety management advice $(0.012)$ & 27 (26) advice $v 13$ (15) no advice \\
\hline \multirow{4}{*}{$\begin{array}{r}\text { Emotional } \\
\text { support }\end{array}$} & Selection of information (0.728) & $\begin{array}{l}17 \text { (19) automatic v } 16 \text { (16) } \\
\text { interactive }\end{array}$ \\
\hline & $\begin{array}{l}\text { Personalisation of information } \\
(0.594)\end{array}$ & $\begin{array}{l}20 \text { (24) personalised } v 12(11) \\
\text { general }\end{array}$ \\
\hline & Anxiety management advice $(0.255)$ & 22 (21) advice $v 12$ (14) no advice \\
\hline & Anxiety at recruitment $(0.013)$ & 31 (20) anxiety $v 10$ (15) no anxiety \\
\hline \multirow{3}{*}{$\begin{array}{l}\text { Negative } \\
\text { interactions }\end{array}$} & Selection of information (0.446) & $\begin{array}{l}36 \text { (39) automatic v } 33 \text { (33) } \\
\text { interactive }\end{array}$ \\
\hline & $\begin{array}{c}\text { Personalisation of information } \\
(0.003)\end{array}$ & $\begin{array}{c}42 \text { (50) personalised } v 24 \text { (22) } \\
\text { general }\end{array}$ \\
\hline & Anxiety management advice $(0.844)$ & 37 (35) advice $v 33$ (37) no advice \\
\hline
\end{tabular}

${ }^{*}$ Scores (from Helgeson's social support questionnaire) were grouped as deteriorating, no change, or improving.

tPredictor variables included in the model (with no interactions) were the three information factors (automatic or interactive selection, personalised or general information, anxiety management advice or none); the continuous variables of age and length of diagnosis; and the categorical variables of sex, newspaper read, coping style (monitoring $v$ blunting), information preference (none or good news only $v$ all information), ${ }^{5}$ and whether had anxiety at recruitment (score $\geq 8$ on hospital anxiety and depression scale).

worsening negative interactions had worsening anxiety $(\mathrm{P}=0.005)$. There was no difference between mean depression scores at baseline (3.4) and follow-up (3.4), nor in the percentage of patients with scores $\geq 8$ at baseline (14\%) and follow-up (13\%).

\section{Discussion}

This study's hypothesis was generated from our previous work ${ }^{11}$ (in which the percentage of cancer patients with anxiety declined from $38 \%$ at recruitment to $19 \%$ at three months among those given personalised information, whereas it remained at $37 \%$ for those given general information only). Those with personalised information were more likely to have shown it to someone else, and we hypothesised that this might lead to improved social support and reduced anxiety. Our current study supports some of the hypothesised mechanisms, but the evidence suggests a more complicated relation between information, social support, and psychological wellbeing.

Patients with personalised information were more likely to think that it told them something new, but the difference in satisfaction between personalised and general booklets was less obvious than previously. Automatically produced booklets were preferred to shorter ones chosen interactively.

There was clear evidence that patients were more likely to show personalised information to confidants and to think that it helped in discussion, but this was not reflected in improvement in measures of social support.

Cross sectional analysis of the data at recruitment and follow-up provides evidence that the quality of the relationship between patients and their confidants (as measured by the "negative factors" scale) was significantly associated with their 
Table 4 Mean change in anxiety and depression scores ${ }^{*}$ for 325 cancer patients from recruitment to follow-up by type of cancer information provided and change in social support scores

\begin{tabular}{|c|c|c|c|c|c|c|}
\hline & \multicolumn{3}{|c|}{ Change in anxiety score at follow-up } & \multicolumn{3}{|c|}{ Change in depression score at follow-up } \\
\hline & \multirow{2}{*}{ Mean (SD) change } & \multicolumn{2}{|c|}{$P$ value $\nmid$} & \multirow{2}{*}{ Mean (SD) change } & \multicolumn{2}{|c|}{$P$ value } \\
\hline & & Corrected & Not corrected & & Corrected & Not corrected \\
\hline \multicolumn{7}{|c|}{ Type of cancer information } \\
\hline \multicolumn{7}{|c|}{ Selection of information: } \\
\hline Automatic & $-0.1(3.1)$ & \multirow{2}{*}{0.28} & \multirow{2}{*}{0.19} & $0.1(2.8)$ & \multirow{2}{*}{0.82} & \multirow{2}{*}{0.57} \\
\hline Interactive & $0.3(2.9)$ & & & $-0.1(2.8)$ & & \\
\hline \multicolumn{7}{|c|}{ Personalisation of information: } \\
\hline Personalised & $-0.4(2.9)$ & \multirow{2}{*}{0.36} & \multirow{2}{*}{0.35} & $0.3(2.8)$ & \multirow{2}{*}{0.06} & \multirow{2}{*}{0.11} \\
\hline General & $0.3(3.0)$ & & & $-0.3(2.8)$ & & \\
\hline \multicolumn{7}{|c|}{ Anxiety management advice: } \\
\hline Advice & $0.1(2.8)$ & \multirow{2}{*}{0.31} & \multirow{2}{*}{0.19} & $0(2.6)$ & \multirow{2}{*}{0.33} & \multirow{2}{*}{0.25} \\
\hline No advice & $0(3.2)$ & & & $0.1(3.0)$ & & \\
\hline \multicolumn{7}{|c|}{ Helgeson's social support scores } \\
\hline \multicolumn{7}{|c|}{ Instrumental support: } \\
\hline Worsening & $0.6(3.2)$ & \multirow{3}{*}{0.61} & \multirow{3}{*}{0.60} & $0.6(3.4)$ & \multirow{3}{*}{0.78} & \multirow{3}{*}{0.56} \\
\hline No change & $-0.2(3.0)$ & & & $-0.1(2.5)$ & & \\
\hline Improved & $0.4(2.6)$ & & & $-0.3(3.0)$ & & \\
\hline \multicolumn{7}{|c|}{ Informational support: } \\
\hline Worsening & $0.2(3.2)$ & \multirow{3}{*}{0.57} & \multirow{3}{*}{0.45} & $0.4(3.4)$ & & \\
\hline No change & $0.2(3.0)$ & & & $0(2.4)$ & 0.03 & 0.04 \\
\hline Improved & $-0.1(2.6)$ & & & $-0.3(2.6)$ & & \\
\hline Emotional supp & & & & & & \\
\hline Worsening & $0.4(3.0)$ & & & $0.7(3.5)$ & & \\
\hline No change & $-0.1(3.0)$ & 0.24 & 0.18 & $-0.3(2.5)$ & 0.37 & 0.40 \\
\hline Improved & $0.3(2.6)$ & & & $0.2(3.0)$ & & \\
\hline Negative interac & & & & & & \\
\hline Worsening & $1.0(3.0)$ & & & $0.7(2.9)$ & & \\
\hline No change & $-0.3(2.7)$ & $<0.001$ & $<0.001$ & $0(1.9)$ & 0.003 & 0.003 \\
\hline Improved & $-0.5(3.1)$ & & & $-0.7(2.9)$ & & \\
\hline
\end{tabular}

*From hospital anxiety and depression scale.

†P values are presented from two general linear models. "Not corrected" is from a model of change in anxiety (or depression) score as a function of the three intervention factors and changes in social support scores (continuous factors). "Corrected" is as above but also corrected for the following factors: cancer type (breast or prostate), age (continuous factor), time (in weeks) since diagnosis (continuous factor), attitude to information, newspaper read, coping style (monitoring or blunting), "Did it change your ideas?" and "Shown it to significant others?"

level of anxiety and depression. This scale includes items such as "Changes the subject when I try to discuss my illness," "Avoids me," "Tells me I look well when I don't," and "Doesn't understand my situation." This measure was a significant predictor, independently, of who the confidant was or whether the patient lived alone. Furthermore, worsening anxiety was associated with worsening negative interactions.

\section{Comparison with previous study}

Comparison of the present study (patients recruited in 2001-3) with our previous one (patients recruited 1996-7) ${ }^{11}$ shows that the catchment population was the same, the rate of refusal to participate was similar $(29 \% v 27 \%)$, and the proportion included in analysis of those randomised was similar $(81 \% v 83 \%)$. Patients from more deprived areas were more likely not to participate in both studies. Unlike in our previous study, however, we found no overall improvement in patient anxiety in this study. The percentage of patients with anxiety at recruitment was lower $(31 \%$ v 38\%) but did not change. There was no relation between anxiety change and intervention or other factors.

Patients in the present study were generally better informed than five years previously. There had been a major improvement in the hospital environment (with the opening of a new building) and much improved access to information, including increased input from Macmillan nurses in the radiotherapy department. The internet was a source of information for a third of patients in the present study, but its impact should not be overstated; $43 \%$ of patients had never used a computer before entering the study. Better information provision might partly explain the lower level of anxiety at baseline, but it cannot explain the absence of the differential effect of personalised versus general information.

\section{Implications of results}

One possible explanation for the different result between this and our previous study is that in the previous study all patients were encouraged to write a list of questions to ask their oncologist one week after the intervention. ${ }^{14}$ Other researchers have shown the possible beneficial effect of prompt sheets and written lists on anxiety. ${ }^{15}$ Although the use of written lists in our previous study $^{10}$ was applied to all groups, it may have led to further reduction in anxiety and possibly had a greater effect in those with personalised information. The other explanation is a chance effect in our earlier study.

The single "information intervention" with anxiety management advice in this study did not reduce levels of anxiety. Although this was based on a successful information intervention for patients with generalised anxiety disorder, it had not previously been tested "on its own" with cancer patients. It is perhaps not surprising that such "information only" interventions have limited impact on psychological symptoms. More proactive methods of cognitive behaviour therapy are more likely to be worth while in the management of cancer related anxiety. ${ }^{16}$

Patients' coping style (according to Miller's classification ${ }^{7}$ ) and information preferences did not seem to have a strong effect on the impact of the different types of information. In our patients the type of newspaper read more often predicted reaction than did coping style. Tabloid readers were more likely to 
think information was too technical, feel overwhelmed, or to have deterioration in perceived informational support.

In this study and our previous one ${ }^{11}$ four out of five patients showed their booklets to family members, whereas only a third of cancer patients given a patient-held record in a general practice study did so. ${ }^{17}$ Why there should be such a big difference is not clear.

\section{Conclusions}

Our present and previous studies suggest that the claim that patients like personalised information and are more likely to show it to their confidant is robust. However, further research is needed into the effects of sharing information on patients' social support and anxiety.

We thank the patients who helped with the study; Joanna Rule for permission for the use of CancerBACUP booklets; Anna Leibowitz and others at CancerBACUP for comments on the study, radiographers and all other colleagues at the Beatson Oncology Centre, Glasgow; colleagues at the University of Plymouth who commented on the paper; colleagues on email lists who visited our website (www.macs.hw.ac.uk/ diana/paccit/ index.htm) and commented on the study design; and Anne Anderson and the PACCIT programme (www.paccit.gla.ac.uk/) for support.

Contributors: RBJ was the principal applicant for funding, led the design and management of the study and the analysis of the data, and wrote the paper. JP contributed to the design of the study, was responsible for all data collection and day to day management of the study, helped with the analysis, and edited the paper. AJC was second applicant for funding, contributed to the design of the study, helped in the development of the computer system, commented on the analysis, and edited the paper. DB was responsible for the development of the computer system and edited the paper. $\mathrm{AB}$ was third applicant for funding, contributed to the design, was responsible for arranging access and clinical support, commented on the analysis, and edited the paper. JW was fourth applicant for funding, contributed to the design, was responsible (with CAW) for the development of the anxiety management advice, and edited the paper. CAW contributed to the design, was responsible (with JW) for the development of the anxiety management

\section{What is already known on this topic}

Anxiety and depression are important comorbidities in cancer and may be affected by provision of information about cancer and by social support

Patients may have different information preferences and coping styles that need to be taken into account in the way cancer information is presented

\section{What this paper adds}

Patients found greater amounts of automatically selected information about cancer more useful than lesser amounts chosen by themselves

The study confirmed that patients were more likely to show personalised information to confidants and others, but a hypothesised link between showing information to confidants and improved social support was not found

This study, unlike an earlier one, showed no difference in anxiety levels between intervention factors, including anxiety management advice advice, and edited the paper. WHG contributed to the design, advised on the analysis, and edited the paper. Neil Craig contributed to the design (an economic analysis was planned) and commented on the paper, but, as the economic analysis was not considered worth while, he is not included as an author.

Funding: This study was funded by the ESRC/EPSRC People at the Centre of Communication and Information Technology (PACCIT) programme (Grant number L328253024).

Competing interests: None declared.

Ethical approval: The Western Local Research Ethics Committee approved the study.

1 Spiegel D, Giese-Davis J. Depression and cancer: mechanisms and disease progression. Biol Psychiatry 2003;54:269-82.

2 De Boer MF, Ryckman RM, Pruyn JF, Van den Borne HW. Psychosocial correlates of cancer relapse and survival: a literature review. Patient Educ Couns 1999;37:215-30.

3 Helgeson VS, Cohen S, Schulz R. Education and peer discussion group interventions and adjustment to breast cancer. Arch Gen Psychiatry 1999;56:340-7.

4 Aymanns P, Filipp S-H, Klauer T. Family support and coping with cancer: some determinants and adaptive correlates. BrJ Soc Psychol 1995;34:107-24.

5 Meredith C, Symonds P, Webster L, Lamont D, Pyper E, Gillis CR, et al. Information needs of cancer patients in west Scotland: cross sectional survey of patients' views. BMJ 1996;313:724-6.

6 Gatherer L. Patient information on cancer-Newspaper read is good predictor of information needs [letter]. BMJ 2000;321:48.

7 Miller SM. Monitoring versus blunting styles of coping with cancer influence the information patients want and need about their disease: implications for cancer screening and management. Cancer 1995;76:167-77.

Fallowfield L. Offering choice of surgical treatment to women with breast cancer. Patient Educ Couns 1997;30:209-14.

9 Kiss A, Meryn S. Effect of sex and gender on psychosocial aspects of prostate and breast cancer. BMJ 2001;323:1055-8.

10 Edwards B, Clarke V. The psychological impact of cancer diagnosis on families: the influence of family functioning and patients' illness characteristics on depression and anxiety. Psycho-oncology 2004;13:562-76.

11 Jones R, Pearson J, McGregor S, Cawsey A, Barrett A, Atkinson JM, et al. Randomised trial of personalised computer based information for cancer patients. BMJ 1999:319:1241-7.

12 Helgeson VS, Cohen S. Social support and adjustment to cancer: reconciling descriptive, correlational, and intervention research. Health Psychol 1996;15:135-48. (Questionnaires obtained from Dr Helgeson at vh2e@andrew.cmu.edu.)

13 Zigmond AS, Snaith RP. The hospital anxiety and depression scale. Acta Psychiatr Scand 1983;67:361-70.

14 Jones R, Pearson J, McGregor S, Barrett A, Gilmour WH, Atkinson JM, et al. Does writing a list help cancer patients ask relevant questions? Patient Educ Couns 2002;47:36971 .

15 Brown RF, Butow PN, Dunn SM, Tattersall MH. Promoting patient participation and shortening cancer consultations: a randomised trial. Br J Cancer 2001;85:1273-9.

16 Febbraro GAR, Clum GA, Roodman AA, Wright JH. The limits of bibliotherapy: a study of the differential effectiveness of self-administered interventions in individuals study of the differential effectiveness of self-administer
with panic attacks. Behavioral Therapy 1999:30:209-22.

17 Drury M, Yudkin P, Harcourt J, Fitzpatrick R, Jones L, Alcock C, et al. Patients with cancer holding their own records: a randomised trial. BrJ Gen Pract 2000;50:105-10. (Accepted 26 January 2006)

doi $10.1136 /$ bmj.38807.571042.68

Faculty of Health and Social Work, University of Plymouth, Drake Circus, Plymouth PL4 8AA

$\mathrm{R}$ B Jones professor of health informatics

Public Health \& Health Policy Section, Division of Community Based Sciences,

University of Glasgow, Glasgow G12 8QQ

$\mathrm{J}$ Pearson research assistant

W H Gilmour senior lecturer in medical statistics

School of Mathematical and Computer Sciences, Heriot Watt University, Riccarton Campus, Edinburgh

A J Cawsey senior lecturer in computing

D Bental research fellow

School of Medicine, University of East Anglia, Norwich NR4 7T]

A Barrett professor of oncology

Greater Glasgow Primary Care NHS Trust, STEPS, Glasgow G42 8AT

J White consultant clinical psychologist

NHS Ayrshire and Arran, Ayrshire Central Hospital, Irvine KA12 8SS

C A White Macmillan consultant in psychosocial oncology

Correspondence to: R Jones ray.jones@plymouth.ac.uk 